\title{
¿Un anacronismo que desacredita toda la narrativa? A propósito de los caballeros romanos en los fragmentos diodoreos de la primera guerra senil
}

\author{
Is the whole narrative discredited by one anachronism? On the subject of the \\ Roman knights in the Diodorean fragments of the first servile war
}

\author{
Fernando Martín Piantanida \\ fmpiantanida@uba.ar \\ Universidad de Buenos Aires. Universidad Nacional de \\ Luján. CONICET - PEFSCEA, Argentina
}

Recepción: 13 Abril 2021

Aprobación: 21 Octubre 2021

Publicación: 01 Diciembre 2021

Cita sugerida: Piantanida, R. (2021). ¿Un anacronismo que desacredita toda la narrativa? A propósito de los caballeros romanos en los fragmentos diodoreos de la primera guerra servil. Sociedades Precapitalistas, 11, e067. https://doi.org/10.24215/22505121e067
Resumen: El presente artículo tiene por objeto analizar la problemática del anacronismo diodoreo sobre los caballeros romanos que actúan como jueces de los gobernadores provinciales y su relación con la credibilidad histórica del resto de su narrativa de la primera guerra servil. En contraposición a una postura historiográfica hipercrítica, se argumenta que el anacronismo no tiene un rol central en el relato del siciliano. Pues la revuelta no se explica por esa afirmación errónea, sino por las referencias a los terratenientes itálicos en la isla y su influencia perniciosa sobre los sicilianos. Por otra parte, cotejando la información de la narrativa diodorea con los indicios procedentes de otras fuentes literarias y epigráficas, se sostiene que Diodoro no parece desconocer la realidad siciliana del siglo II a.C. y que su anacronismo no socava el valor histórico de los otros fragmentos conservados.

Palabras clave: Anacronismo, Caballeros romanos, Narrativa diodorea, Fragmentos, Primera guerra servil, Hipercriticismo, Itálicos.

\begin{abstract}
The purpose of this article is to analyze the problem of Diodorean anachronism about the Roman knights who act as judges of the provincial governors and its relationship with the historical credibility of the rest of his narrative of the first servile war. In contrast to a hypercritical historiographic position, it is argued that anachronism does not play a central role in the Diodorus' account. For the revolt is not explained by this erroneous statement, but by the references to the Italian landowners in the island and their bad influence on the Sicilians. On the other hand, by comparing the information of the Diodorean narrative with the evidence from other literary and epigraphic sources, it is argued that Diodorus does not seem to be unaware of the Sicilian reality of the second century BC and that his anachronism does not undermine the historical value of the other preserved fragments.
\end{abstract}

Keywords: Anachronism, Roman knights, Diodorean narrative, Fragments, First servile war, Hypercriticism, Italics. 


\section{INTRODUCCIÓN}

Desde mediados del siglo pasado resulta un lugar común de la crítica erudita advertir que Diodoro Sículo cometió un flagrante anacronismo cuando, en su narrativa de la primera guerra servil (c. 139-132 a.C.), afirma que los gobernadores romanos de Sicilia no podían impedir el bandidismo de los esclavos-pastores promovido por sus amos porque la mayoría de estos eran caballeros romanos que actuaban como jueces en los tribunales competentes en causas de extorsión iniciadas contra los exgobernadores, razón por la cual los pretores en ejercicio se vieron compelidos a la connivencia ${ }^{1}$. Pero generalmente los historiadores modernos subsanan el error reemplazando a los equites, con sus atribuciones legales sobre dichas cortes, por otros latifundistas poderosos, sin por ello desacreditar el resto de la narrativa diodorea ${ }^{2}$.

Sin embargo, algunos autores de una corriente historiográfica según la cual las comúnmente llamadas guerras serviles de la República romana fueron en verdad revueltas provinciales contra el poder romano, hacen hincapié precisamente en ese error de Diodoro para desacreditar otros aspectos de su narrativa de la insurrección o incluso toda ella. Esta postura hipercrítica es sostenida por Verbrugghe (1972: 559), quien se sirve del anacronismo de los equites para hacer un argumento por analogía tendiente a rechazar la descripción de la economía siciliana provista por Diodoro ${ }^{3}$ y más recientemente es desarrollada en profundidad por Morton (2018b). Para este último autor, el anacronismo tiene un rol central en el relato diodoreo y no se lo puede corregir reemplazando a los caballeros romanos que allí se mencionan por terratenientes poderosos -como habitualmente se hace- sin cuestionar toda la estructura narrativa de la revuelta, y tampoco se puede asumir que el resto de ella sea preciso ${ }^{4}$. Según el erudito británico, el irresponsable accionar de los terratenientes de Sicilia exhortando a sus esclavos-pastores a conseguir su propia subsistencia por medio del bandidismo requiere la protección legal de los amos por su rol de jueces en las cortes que traban las acusaciones de extorsión. Ambos elementos son necesarios en la narrativa diodorea, la cual, además, demuestra una desconexión de la realidad siciliana del siglo II a.C. ${ }^{5}$ que escasamente conocemos por otras fuentes, especialmente en lo que concierne a dos puntos: la forma del gobierno romano en la provincia (sin tropas enviadas desde Roma, sino utilizando levas locales que eran un signo de la pujanza de las póleis sicilianas) y las prácticas de explotación servil desplegadas por los amos (el bandidismo no sería un acto criminal que deshumaniza a los esclavos tal y como lo describe Diodoro sino la utilización de tierra pública en el marco de un peculium concedido a los esclavos-pastores).

El presente artículo tiene por objeto analizar específicamente la problemática del anacronismo diodoreo sobre los caballeros romanos que actúan como jueces de los gobernadores provinciales y su relación con la credibilidad histórica del resto de su narrativa de la primera guerra servil ${ }^{6}$. Para llevar a cabo esta tarea dividiremos nuestro trabajo en dos partes. En primer lugar, describiremos sintéticamente el estado de conservación del relato diodoreo (factor fundamental para comprender las divergencias en torno a su interpretación), y traduciremos y examinaremos los fragmentos donde se halla el error relativo a los equites. En segundo lugar, refutaremos la postura historiográfica hipercrítica del anacronismo procediendo del siguiente modo: veremos la función que el anacronismo cumple en la narrativa, a nuestro juicio menor frente al rol desempeñado por los latifundistas itálicos; cotejaremos las referencias diodoreas a estos últimos con otras fuentes literarias y epigráficas ${ }^{7}$; utilizaremos algunos indicios provenientes de la arqueología moderna y de otros autores antiguos para mostrar que Diodoro no parece desconocer la realidad siciliana del siglo II a.C.; finalmente, sostendremos que resulta muy cuestionable tratar al historiador sículo como un mero copista acrítico desprovisto de toda inteligencia. 


\section{El ESTADO DE CONSERVACIÓN DEL RELATO DIODOREO DE LA PRIMERA GUERRA SERVIL Y EL ANACRONISMO DE LOS IPPEÎS TÔN ROMAÍON}

Diodoro narró la primera revuelta servil de Sicilia en los libros XXXIV-XXXV de la Bibliothéke historikê ${ }^{8}$, y la segunda en el XXXVI. Pero estos libros no han llegado completos hasta nuestra época ${ }^{9}$. Sus relatos de las guerras serviles sicilianas solo se conservan de manera fragmentaria a través de dos versiones bizantinas. Por un lado, algunos fragmentos discontinuos de los libros originales de Diodoro reagrupados en una colección temática del siglo X que ordenó escribir el emperador bizantino Constantino VII, conocida actualmente como Excerpta Constantiniana ${ }^{10}$. Por otro lado, un resumen del siglo anterior hecho por el patriarca Focio e incluido en su Myrióbiblos, una obra compuesta de sus reseñas bibliográficas de los libros que leyó. La estructura narrativa del resumen fociano resulta fundamental para ordenar cronológicamente los hechos de las revueltas, pues esto se hace muy difícil con la versión de los Excerpta ${ }^{11}$.

Por lo tanto, el relato diodoreo de la primera guerra servil -y también el de la segunda- pervive de forma mutilada y lagunosa: fragmentos provenientes de dos versiones bizantinas diferentes con amplios vacíos, inconsistencias y descontextualizaciones. Todo lo cual hace de esta narrativa una suerte de rompecabezas cuya reconstrucción se presta consecuentemente a interpretaciones disímiles.

Pasemos ahora a traducir y examinar el anacronismo diodoreo relativo a los caballeros romanos. Según el resumen de Focio, Diodoro (34/35.2.3) dice lo siguiente:

"Los gobernadores intentaban contener [a los bandidos] pero no osaban castigar[los] a causa de la fuerza y de la autoridad de los amos que mandaban a los bandidos, y eran obligados a permitir que la provincia fuese librada al bandidaje. Pues la mayoría de los dueños [de esclavos] eran caballeros romanos, por lo cual devenían jueces de los gobernadores acusados por las provincias y eran temidos por tomar la iniciativa contra ellos".

Conforme al fragmento equivalente de la versión de los Excerpta Constantiniana, Diodoro (34/35.2.31) señala:

"Los gobernadores intentaban contener la locura de los esclavos, pero no osaban castigar[los] a causa de la fuerza y de la autoridad de los amos, y eran obligados a permitir que la provincia fuese librada al bandidaje. Pues la mayoría de los dueños [de esclavos] eran caballeros romanos de pleno derecho, por lo cual devenían jueces de los gobernadores acusados por las provincias y eran temidos por tomar la iniciativa contra ellos".

Ambos fragmentos equivalentes son muy similares entre sí desde el punto de vista léxico y semántico, podríamos decir casi idénticos, por lo cual deben reproducir con relativa fidelidad el texto original de Diodoro. En ellos, la aserción concerniente al rol de jueces que ejercen los equites es errónea, pues su control de los tribunales competentes en las acusaciones de concusión iniciadas contra los gobernadores provinciales es posterior a la primera guerra servil: data de la lex repetundarum de Cayo Graco del 123 o 122 a.C. ${ }^{12}$ El mismo Diodoro posteriormente en su obra (34/35.25) atribuye correctamente la ley al hermano menor de Tiberio. A menudo los eruditos modernos imputan el error a la supuesta fuente de Diodoro, Posidonio de Apamea, por su presunta aversión hacia el orden ecuestre ${ }^{13}$.

No obstante, pese a este evidente anacronismo, nos parece excesiva la argumentación según la cual el error pone en entredicho el resto de los fragmentos diodoreos de la primera guerra servil. Destinamos el siguiente apartado -la segunda parte del presente estudio- a criticar esa postura historiográfica, para lo cual nos enfocaremos en las referencias a los itálicos y en otros aspectos de la representación diodorea de la isla en la época de la revuelta. 


\section{Diodoro, los Italikoí y la Sicilia del Siglo II A.C.}

Con respecto al argumento historiográfico que tiende a desacreditar toda o buena parte de la narrativa diodorea de la primera guerra servil en base al anacronismo de los equites, formulamos las siguientes críticas. En primer lugar, según nuestra lectura de los fragmentos, no creemos que esa aserción errónea resulte central en la narrativa, al menos no en el sentido de que sea la causa de la revuelta. Más bien se trata de un factor que agrava el bandidismo incitado por los amos, pues imposibilita su contención por parte de los gobernadores romanos, pero no lo genera.

Incluso despojando a esos grandes terratenientes de su eventual rol de jueces (kritai) en las cortes por concusión, lo cual ciertamente cercena una parte de su poder, que en los términos de los fragmentos D.S. 34/35.2.3 y 34/35.2.31 podría ser su autoridad (báros), no obstante, no pierden todo su poder, pues aún conservan la fuerza (iskhyss) ${ }^{14}$ derivada de su condición de latifundistas y propietarios de numerosos esclavos, que se manifiesta cuando Diodoro dice que Damófilo se desplazaba por la campaña siciliana con una guardia personal de esclavos armados (34/35.2.34.7-9). Entonces, no resulta inverosímil pensar a estos terratenientes como agentes de poder con los cuales los pretores debieron necesariamente negociar, más aún si el dominio imperial no se ejercía con tropas regulares asentadas en la provincia.

En cambio, lo que resulta central para el origen de la revuelta, según los hechos recogidos del relato diodoreo, es la presencia de itálicos o romano-itálicos en la isla ${ }^{15}$ actuando como grandes propietarios de tierras y de esclavos y ejerciendo una influencia perniciosa sobre los sicilianos ricos, pero sin que sea determinante su condición jurídica de caballeros y su eventual rol de jueces. En efecto, para Diodoro las causas de las revueltas serviles residen fundamentalmente en "los malos tratos de los amos" (kakoukhias [...] tôn despotôn) a sus esclavos (D.S. 34/35.2.26), entendidos como un comportamiento afectado por la soberbia (byperephania), la cual es contrapuesta a la moderación (epieikeia) ${ }^{16}$. Y son los italianos los que introdujeron la explotación servil a gran escala en Sicilia para obtener el máximo beneficio ${ }^{17}$, maltratando a sus esclavos, sin proveerles suficiente comida, e incitándolos al bandidaje, convirtiéndose así en un mal ejemplo que los terratenientes sicilianos -representados por Damófilo y su esposa Megallis- imitan (D.S. 34/35.2.32 $=34 / 35.2 .27)$. Esto se manifiesta de manera diáfana en dos fragmentos procedentes de la colección de Constantino. Por una parte, cuando Diodoro (34/35.2.27.8-28.1) dice:

"Pues los sicilianos que habían adquirido mucha riqueza competían con los italianos en soberbia, codicia y maldad. En efecto, los italianos que habían adquirido muchos esclavos condujeron a los pastores hacia tal hábito criminal porque no les suministraban alimentos, sino que les permitían el bandidaje".

Por otra parte, cuando Diodoro (34/35.2.34.1-7) habla del siguiente modo del amo cuyos esclavos comenzaron la revuelta:

"Había un tal Damófilo, nativo de Enna, muy rico, de conducta soberbia, quien, cultivando un gran circuito de tierras y habiendo adquirido muy numerosos rebaños de ganados, no solo emulaba [ezélosen] el lujo de los italianos en Sicilia [tôn katà Sikelian Italikôn], sino también la multitud de sus esclavos y su inhumanidad y dureza contra ellos”.

Como se observa, los que iniciaron en la isla la explotación servil a gran escala e incitaron a robar a sus esclavos-pastores, cuyo resultado fue la revuelta, son los latifundistas itálicos ${ }^{18}$. Por consiguiente, son estos los principales culpables de la insurrección, aunque luego Diodoro explicite que quien causó la ruina de su país fue el propio Damófilo (34/35.2.35). Por otra parte, el poder derivado de la actuación como jurados en los tribunales por extorsión no parece ser un requisito indispensable para que los amos estimulen el bandidismo de sus esclavos-pastores, al menos Damófilo no es un caballero romano ${ }^{19}$ ni se ampara en su eventual rol de juez cuando en la narrativa se indica cómo exhortaba a sus esclavos al bandidismo (D.S. 34/35.2.38).

En segundo lugar, y consecuentemente con la centralidad que para nosotros tiene la responsabilidad de los terratenientes itálicos en los fragmentos diodoreos de la revuelta, creemos que la atención de la crítica 
moderna debería concentrarse en dichas referencias. Pues, si nuestra lectura es correcta, para impugnar el valor histórico de la narrativa del siciliano más bien habría que refutar sus aserciones relativas a una importante presencia de latifundistas romanos e itálicos en la Sicilia del siglo II a.C. ${ }^{20}$, cuestión que ha sido muy discutida entre los eruditos ${ }^{21}$. No es nuestra intención tratar exhaustivamente este debate, ni mucho menos resolverlo. Simplemente nos limitamos a destacar lo siguiente. Diodoro utiliza cinco gentilicios diferentes para hablar de los latifundistas residentes en la isla para la época de la primera guerra servil: Sikelós (siciliano nativo que habitaba la isla antes de la llegada de los griegos); Sikeliótes (habitante griego de Sicilia) ${ }^{22}$; Italiótes (habitante griego de Italia); Italikós (italiano o itálico); y Româ̂os (romano). Sin embargo, a menudo los estudiosos modernos -historiadores y traductores- los reagrupan en tres: Sikeloi/Sikeliôtai como "sicilianos"; Italiôtai/Italikoí como "italianos" o "itálicos"; y Romaîoi como "romanos"23. Agregamos que a nuestro entender- Diodoro parece utilizar Italiótes e Italikós como sinónimos, al menos esto inferimos de su uso alternativo en el mismo fragmento 34/35.2.27. Por lo tanto, se pueden simplificar los gentilicios señalando que Diodoro habla de sicilianos, caballeros romanos e italianos como grandes terratenientes, lo cual -más allá de que resulte imposible dilucidar el origen de la mayoría, según él compuesta de equites-es cuando menos verosímil, puesto que la presencia romano-itálica en la Sicilia del siglo II a.C., o incluso antes, se ve confirmada por otras fuentes literarias y epigráficas.

En efecto, con respecto a las fuentes literarias, se pueden mencionar las siguientes referencias. Por una parte, Livio (29.1.16) habla de "algunos oriundos de Italia" ${ }^{24}$ (quibusdam Italici generis) en el contexto del reclutamiento de tropas en Siracusa o sus alrededores realizado por Escipión en el 205 a.C., durante la segunda guerra púnica. Por otra parte, Floro (2.7.3), muy probablemente retomando a Tito Livio ${ }^{25}-$ cuya fuente o fuentes de la primera guerra servil podrían provenir de una tradición diferente de la de Diodoro $^{26}$ - señala la presencia de ciudadanos romanos como latifundistas en Sicilia para la época de la revuelta: "Tierra feraz en trigo y provincia, en cierta forma aledaña, estaba ocupada por los latifundios de ciudadanos romanos" ${ }^{27}$ (Terra frugum ferax et quodam modo suburbana provincia latifundiis civium Romanorum tenebatur). Finalmente, Cicerón (Verr. 2.2.32.), refiriéndose al procedimiento establecido por la lex Rupilia, menciona la elección de jueces procedentes de colonias romanas, lo cual implicaría -como afirma Dumont, 1987: 217, n. 313- que estas ya estarían bien establecidas en Sicilia para el 132 a.C.

En lo que concierne a las fuentes epigráficas, si bien escasas ${ }^{28}$, no obstante son significativas para apoyar una temprana presencia romano-itálica en la isla, y señalamos las dos siguientes que resultan muy conocidas: por un lado, la famosa inscripción en piedra llamada a menudo elogium de Polla ${ }^{29}$, siempre y cuando se considere que ella verdaderamente refiere a la primera guerra servil o al bandidismo que la precedió, y que los esclavos capturados de los que habla (fugiteiuos Italicorum) eran de propietarios italianos residentes en la isla, en la senda interpretativa de Mommsen $^{30}$; por otro lado, una epigrafía de la ciudad siciliana de Halesa que fue dedicada por unos Italicei a Lucio Cornelio Escipión Asiático ${ }^{31}$, pretor en la isla en el 193 a.C., razón por la cual data de comienzos del segundo siglo.

En tercer lugar, y concerniente a la mencionada desconexión entre Diodoro y la realidad de Sicilia en el siglo II a.C., señalamos lo siguiente. Por una parte, el anacronismo cierra el prólogo de la revuelta, donde también se indica que la isla llevaba sesenta años de prosperidad luego de la finalización de la segunda guerra púnica, un aspecto que las recientes investigaciones arqueológicas confirman poniendo de relieve un auge de la construcción edilicia de las ciudades sicilianas financiada por el evergetismo de sus élites (Wilson 2000: 144 y 2013: 488-489; Soraci 2016: 64-71). Por otra parte, si las levas locales también expresan la vitalidad de las ciudades sicilianas mediante la institución del gymnásion, espacio de esparcimiento y preparación militar para las élites urbanas cuyos reclutas colaboraban en mantener la ley y el orden, permitiendo así un mínimo de fuerzas romanas en la isla (Prag, 2007), debería advertirse que dichas levas no están ausentes en la narrativa diodorea. En efecto, en los comienzos de ambas revuelas Diodoro indica que los pretores utilizaron tropas conformadas por soldados sicilianos (para la primera y la segunda revuelta, véase 34/35.2.18 y 36.4 
respectivamente), lo cual se corresponde a una primera evaluación de los hechos por parte de las autoridades romanas como meras acciones de bandidismo o conspiraciones serviles menores, usualmente reprimidas con operaciones de policía realizadas por milicias locales. Con posterioridad, las revueltas fueron reevaluadas como guerras y entonces se enviaron cónsules con tropas regulares (Hoben, 1978: 116-120). Finalmente, en cuanto al bandidismo de los esclavos-pastores, no solo Diodoro habla de él como una actividad criminal que precede a la primera guerra servil, sino también otras fuentes literarias (Str. 6.2.6; Ionn. Ant., fr. 61), aunque difieren sobre la responsabilidad que les cabe a los amos ${ }^{32}$.

En cuarto lugar, creemos que centrarse en el anacronismo o señalar que Diodoro narra sin comprender ${ }^{33}$, se relaciona con un tópico de la visión tradicional sobre la Bibliothéke historiké que proviene de la filología alemana decimonónica y consiste en tratar a Diodoro como un copista acrítico ${ }^{34}$, algo que resulta muy cuestionable a la luz de los estudios recientes que conforman una corriente revisionista de la obra del siciliano $^{35}$. Estos muestran que Diodoro fue un compilador con criterio que manejó un ingente material para escribir su historia universal ${ }^{36}$. Además, agregamos que, para el caso de las revueltas serviles sicilianas, Diodoro - más allá de las fuentes escritas que haya utilizado- tenía autopsia del lugar ${ }^{37}$. Por otra parte, Green (2006: 29-30) señala que el siciliano -como todos los historiadores antiguos- cometía errores, pero ellos deben ser explicados de manera racional, no adscribiéndoselos a su supuesta incompetencia, y, en un proyecto de cuarenta libros escritos con pergaminos los errores eran inevitables, aún más teniendo en cuenta que dejó incompleta la revisión final de su obra. En este sentido, por un lado, como sostiene Dumont (1987: 215), es posible que el anacronismo de los equites sea producto de una única introducción para ambas guerras serviles presente en una fuente monográfica utilizada por Diodoro, y un mal recorte de los materiales no altera su valor; por otro lado, siguiendo a Goukowsky (2014: 321-322, n. 29), conviene relativizar el anacronismo, pues Diodoro parece haber sido el ejemplar más temprano de una larga y atestiguada tradición que confunde la autoría de la lex repetundarum de Cayo Graco con su hermano mayor Tiberio.

\section{Conclusión}

El relato diodoreo de la primera guerra servil pervive de forma mutilada y lagunosa mediante fragmentos que proceden de dos versiones bizantinas diferentes, con amplios vacíos, inconsistencias y descontextualizaciones. Por consiguiente, su reconstrucción se presta a interpretaciones disímiles por parte de los eruditos modernos.

En el presente artículo hemos examinado la problemática del anacronismo diodoreo sobre la actuación de los equites como jueces de los gobernadores en los procesos por extorsión iniciados contra ellos y su relación con la credibilidad histórica del resto de su narrativa. Del análisis realizado -conforme a nuestra interpretación de los fragmentos- se deriva lo siguiente: el anacronismo no tiene un rol central en el relato diodoreo, pues la revuelta no se explica por esa afirmación errónea, sino principalmente por las referencias a los terratenientes itálicos en la isla; el cotejo de estas últimas con otras fuentes literarias y epigráficas apunta a reforzar la plausibilidad de la presencia romano-itálica señalada por el siciliano, y algunas de ellas (Floro) precisan su rol de latifundistas; por otra parte, Diodoro no parece desconocer la realidad siciliana de mediados del siglo II a.C., al menos por cuanto se puede recabar de algunos indicios arqueológicos y de su cruce con otros autores antiguos; finalmente, resulta muy cuestionable presuponer al historiador sículo como un mero copista acrítico e incompetente. Todo lo cual nos lleva a rechazar la postura historiográfica hipercrítica del anacronismo y a sostener que, si bien Diodoro cometió un flagrante error, esto no desacredita el valor histórico del resto de sus fragmentos de la primera guerra servil.

\section{BibLiografía}

Adamo, M. (2016). The lapis Pollae: date and contexts. Papers of the British School at Rome, 84, 73-100. 
Ambaglio, D. (1995). La Biblioteca storica di Diodoro Siculo: Problemi e metodo. Como: New Press.

Barca, N. (2020). Rome's Sicilian Slave Wars: The Revolts of Eunus and Salvius, 136-132 and 105-100 BC. Barnsley: Pen \& Sword.

Bernard, S. G., Damon, C. \& Grey, C. (2014). Rhetorics of Land and Power in the Polla Inscription (CIL I ${ }^{2}$ 638). Mnemosyne, 67(6), 953-985.

Bertrac, P. \& Chamoux, F. (1993). Introduction générale. En P. Bertrac, F. Chamoux \& Y. Vernière. Diodore de Sicile. Bibliothèque Historique, Livre I (pp. vii-lxxvi). Paris: Les Belles Lettres.

Bradley, K. R. (1998). Slavery and Rebellion in the Roman World, 140 B.C.-70 B.C. Bloomington: Indiana University Press.

Brunt, P. A. (1971). Italian manpower: 225 B.C.-A.D. 14. Oxford: Clarendon Press.

Brunt, P. A. (1973). Conflictos sociales en la República romana. Buenos Aires: EUDEBA.

Canfora, L. (1999). Diodoro Siculo. La rivolta degli schiavi in Sicilia. Palermo: Sellerio.

Capozza, M. (1974-1975). Il brigantaggio nelle fonti della prima rivolta servile siciliana. Atti dell'Istituto Veneto di Scienze, Lettere ed Arti, 133, 27-40.

Capozza, M. (1977). Giovanni Antiocheno, Frgg. 44, 47, 61 Müller. Historia: Zeitschrift für Alte Geschichte, 26(4), 385-414.

Carcopino, J. (1906). La Sicile Agricole au dernier Siècle de la République Romaine. Vierteljahrschrift Für Sozial- Und Wirtschaftsgeschichte, 4(1), 128-185.

Chamoux, F. (1990). Un historien mal-aimé: Diodore de Sicile. Bulletin de l'Association Guillaume Budé, 3, 243-252.

Coarelli, F. (1981). La Sicilia tra la fine della guerra annibalica e Cicerone. En A. Giardina \& A. Schiavone (eds.). Società romana e produzione schiavistica. Vol. I, L'Italia: insediamenti e forme economiche (pp. 1-18 y 457-459). Bari: Laterza.

Corsaro, M. (1998). Ripensando Diodoro. Il problema della storia universale nel mondo antico. Mediterraneo Antico, I(2), 405-436.

Crawford, M. H. (1982). La República romana. Madrid: Taurus.

Dumont, J.-C. (1987). Servus: Rome et l'esclavage sous la république. Rome: École française de Rome.

Forrest, W. G. G. \& Stinton, T. C. W. (1962). The First Sicilian Slave War. Past \& Present, 22, 87-93.

Forster, E. S. (1947). Lucius Annaeus Florus. Epitome of Roman History. Cambridge, MA: Harvard University Press.

Frank, T. (1935). On the Migration of Romans to Sicily. The American Journal of Philology, 56(1), 61-64.

Fraschetti, A. (1981). Per una prosopografia dello sfruttamento: romani e italici in Sicilia (212-44 a. C.). En A. Giardina \& A. Schiavone (eds.). Società romana e produzione schiavistica. Vol. I, L'Italia: insediamenti e forme economiche (pp. 51-77 y 474-480). Bari: Laterza.

Goukowsky, P. (2014). Diodore de Sicile. Bibliothèque Historique, Fragments, Tome IV, Livres XXXIII-XL. Paris: Les Belles Lettres.

Green, P. (1961). The First Sicilian Slave War. Past \& Present, 20, 10-29.

Green, P. (2006). Diodorus Siculus, Books 11-12.37.1: Greek History 480-431 B.C., the Alternative Version. Austin: University of Texas Press.

Hinojo, G. \& Moreno, I. (2000). Floro. Epitome de la Historia de Tito Livio. Madrid: Gredos.

Hoben, W. (1978). Terminologische Studien zu den Sklavenerhebungen der römischen Republik. Wiesbaden: Franz Steiner Verlag.

Hornblower, J. (1981). Hieronymus of Cardia. Oxford: Oxford University Press.

Jal, P. (1967). Florus. CEuvres. Tome I. Paris: Les Belles Lettres.

Konrad, C. F. (2006). From the Gracchi to the First Civil War (133-70). En N. S. Rosenstein \& R. Morstein-Marx (eds.). A companion to the Roman Republic (pp. 167-189). Malden, Mass: Blackwell Publishing. 
Lintott, A. (2006). Political history, 146-95 B.C. En J. A. Crook, A. Lintott \& E. Rawson (eds.). The Cambridge Ancient History. Vol. IX: The Last Age of the Roman Republic, 146-43 B.C. (pp. 40-103). Cambridge: Cambridge University Press.

López Barja de Quiroga, P. (2004). El toro contra la loba. De los Graco a la guerra de los aliados. En P. López Barja de Quiroga \& F. J. Lomas Salmonte. Historia de Roma (pp. 106-131). Madrid: Akal.

Manganaro, G. (1967). Über die zwei sklavenaufstande in Sizilien. Helikon, 7, 205-222.

Manganaro, G. (1972). Per una storia della Sicilia romana. En $A N R W I, I$ (pp. 442-461). Berlin-New York: De Gruyter.

Manganaro, G. (1980). La provincia romana. En E. Gabba \& G. Vallet (eds.). La Sicilia antica II, 2 (pp. 411-461). Napoli: Storia di Napoli e della Sicilia.

Manganaro, G. (1982). Monete e ghiande inscritte degli schiavi ribelli in Sicilia. Chiron, 12, 237-244.

Manganaro, G. (1983). Ancora sulle rivolte 'servili' in Sicilia. Chiron, 13, 405-409.

Manganaro, G. (2012). Pace e guerra nella Sicilia tardo-ellenistica e romana (215 a.C.-14 d.C.): Ricerche storiche e numismatiche (Nomismata 7). Bonn: Habelt Verlag.

Mazza, M. (1981). Terra e lavoratori nella Sicilia tardorepubblicana. En A. Giardina \& A. Schiavone (eds.). Società romana e produzione schiavistica. Vol. I, L'Italia: insediamenti e forme economiche (pp. 19-49 y 459-473). Bari: Laterza.

Mazza, M. (1985). Sul lavoro servile nella Sicilia romana. Ideologia ed antropologia in un passo di Diodoro (XXXIV/ XXXV 2, 28-30). En H. Kreißig \& F. Kühnert (eds.). Antike Abhängigkeitsformen in den griechischen Gebieten ohne Polisstruktur und den römischen Provinzen. Actes du Colloque sur l'esclavage, Iéna, 29 septembre-2 octobre 1981 (pp. 99-107). Berlin: Akademie-Verlag.

Mommsen, T. (ed.). (1863). Corpus Inscriptionvm Latinarvm I: Inscriptiones latinae antiquissimae ad C. Caesaris mortem. Berolini: apud Georgivm Remervm.

Morton, P. (2013). Eunus: The cowardly King. The Classical Quarterly, 63(1), 237-252

Morton, P. (2018a). Diodorus Siculus' 'slave wars' narratives: writing social commentary in the Bibliothēkē, The Classical Quarterly, 68(2), 534-551.

Morton, P. (2018b). Filling in the Gaps: Studying Anachronism in Diodorus' Narrative of the First Sicilian 'Slave War'. Histos, Supplement 8, 115-143. Recuperado de https://histos.org/documents/SV08.Ch.4.MortonFillingi nGaps.pdf

Muntz, C. E. (2017). Diodorus Siculus and the World of the Late Roman Republic. New York: Oxford University Press.

Pareti, L. (1927). I supposti 'sdoppiamenti' delle guerre servili in Sicilia. Rivista di Filologia e di Istruzione Classica, 5, 44-67.

Pareti, L. (1953). Storia di Roma e del mondo romano III. Dai prodromi della III guerra Macedonica al 'primo triumvirato' (170-59 av. Cr.). Torino: Unione tipografico-editrice torinese.

Pfuntner, L. (2015). Reading Diodorus through Photius: The case of the Sicilian Slave Revolts. Greek, Roman, and Byzantine Studies, 55(1), 256-272. Recuperado de https://grbs.library.duke.edu/article/view/15229

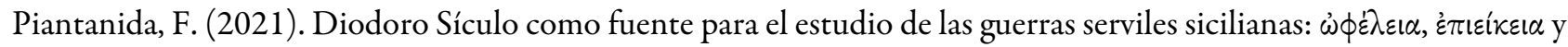

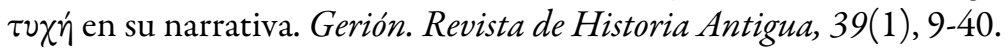

Pinzone, A. (2012). Dall'epitropé di Diodoro ai possessorum intemperantes motus di Cassiodoro. En A. Pinzone, E. Caliri \& R. Arcuri (eds.). Forme di dipendenza nelle società ditransizione: Atti del XXXII Colloquio Internazionale G.I.R.E.A. Messina 15-17 maggio 2008 (pp. 139-153), Messina: Dipartimento di Scienze dell'Antichità dell'Università di Messina.

Pinzone, A. (2015). Aspetti temporali e spaziali nei frammenti diodorei sulle guerre servili siciliane. En A. Beltrán, I. Sastre \& M. Valdés (eds.). Los espacios de la esclavitud y la dependencia desde la antigüedad. Actas del XXXV coloquio del GIREA. Homenaje a Domingo Plácido, Madrid 28-30 novembre 2012 (pp. 351-364), Besançon: Presses Universitaires de Franche-Comté. 
Prag, J. (2007). Auxilia and Gymnasia: A Sicilian Model of Roman Imperialism. The Journal of Roman Studies, 97, 68-100.

Rathke, G. (1904). De Romanorum bellis servilibus capita selecta. Berolini: apud Georgium Nauck (Fr. Rühe).

Rathmann, M. (2016). Diodor und seine Bibliotheke: Weltgeschichte aus der Provinz. Berlin: De Gruyter.

Roberto, U. (2009). Byzantine Collections of Late Antique Authors: Some Remarks on the Excerpta historica Constantiniana. En L. Mecella \& M. Wallraff (eds.). Die Kestoi des Julius Africanus und ibre Überlieferung (pp. 71-84). Berlin: De Gruyter.

Sacks, K. S. (1990). Diodorus Siculus and the First Century. Princeton: Princeton University Press.

Sánchez León, Ma L. (1991). Revueltas de esclavos en la crisis de la República. Madrid: Akal.

Sánchez León, Ma L. (2002). La monarquía de Euno-Antíoco. Documentación y problemática. Mayurqa, 28, 215-222.

Sánchez León, Ma L. (2004a). Adorando a Deméter. Euno-Antíoco y la diosa de Enna. Gerión. Revista de Historia Antigua, 22(1), 135-145.

Sánchez León, Ma L. (2004b). La amonedación del Basileus Antíoco en Sicilia (siglo II a.C.). En F. Chaves Tristán \& F.J. García Fernández (eds.). Moneta qua scripta. La moneda como soporte de escritura. Actas del III Encuentro Peninsular de Numismática Antigua, Osuna (Sevilla) Febrero-Marzo 2003 (pp. 223-228). Sevilla.

Schwartz, E. (1903). Diodoros 38. En RE 5 (pp. 663-704).

Shaw, B. D. (2001). Spartacus and the Slave Wars: A Brief History with Documents. Boston-New York: Bedford/St. Martin's.

Soraci, C. (2016). La Sicilia romana, Secc. III a.C.-V d.C. (Studi storici Carocci 267). Roma: Carocci editore.

Stampacchia, G. (1976). La Tradizione della Guerra di Spartaco da Sallustio a Orosio. Pisa: Giardini.

Stylianou, P. J. (1998). A historical commentary on Diodorus Siculus, book 15. Oxford: Clarendon Press.

Urbainczyk, T. (2008). Slave Revolts in Antiquity. Berkeley-Los Angeles: University of California Press.

Verbrugghe, G. P. (1972). Sicily 210-70 B. C.: Livy, Cicero and Diodorus. Transactions and Proceedings of the American Philological Association, 103, 535-559.

Verbrugghe, G. P. (1973). The Elogium from Polla and the First Slave War. Classical Philology, 68(1), 25-35.

Verbrugghe, G. P. (1974). Slave Rebellion or Sicily in Revolt?, Kokalos, 20, 46-60.

Villar Vidal, J. A. (1993). Tito Livio. Historia de Roma desde su fundación. Libros XXVI-XXX. Madrid: Gredos.

Volquardsen, C. A. (1868). Untersuchungen über die Quellen der griechischen und sicilischen Geschichten bei Diodor, Buch XI bis XVI. Kiel: Schwers'sche Buchhandlung.

Walton, F. R. (1967). Diodorus Siculus. The Library of History, Volume XII: Fragments of Books 33-40. Cambridge, MA: Harvard University Press.

Westermann, W. L. (1955). The slave systems of Greek and Roman antiquity. Philadelphia: American Philosophical Society.

Wilamowitz-Moellendorff, U. V. (1907). Die griechische Literatur des Altertums. En K. Krumbacher, J. Wackernagel \& U. V. Wilamowitz-Moellendorff. Die griechische und lateinische Literatur und Sprache (pp. 3-328). BerlinLeipzig: Teubner.

Wilms, A. (1885). Über die Quellen für die Geschichte des ersten Sklavenkrieges. Hamburg: Wilhelm-Gymn.

Wilson, A.J. N. (1966). Emigration from Italy in the republican age of Rome. Manchester: Manchester University Press.

Wilson, R. J. A. (2000). Ciceronian Sicily: an archaeological perspective. En C. Smith \& J. Serrati (eds.). Sicily from Aeneas to Augustus: New Approaches in Archaeology and History (pp. 134-160). Edinburgh: Edinburgh University Press.

Wilson, R. J. A. (2013). Becoming Roman Overseas? Sicily and Sardinia in the Later Roman Republic. En J. D. R. Evans (ed.). A companion to the archaeology of the Roman Republic (pp. 485-504). Malden: Wiley Blackwell.

Wiseman, T. P. (1964). Viae Anniae. Papers of the British School at Rome, 32, 21-37. 
Yarrow, L. M. (2006). Historiography at the End of the Republic: Provincial Perspectives on Roman Rule. Oxford: Oxford University Press.

Yavetz, Z. (1991). Slaves and slavery in ancient Rome. New Brunswick-New Jersey: Transaction Publishers.

\section{Notas}

1 Véase e.g. Walton (1967: 57, n. 2) = Yavetz (1991: 24, n. 2); Goukowsky (2014: 321-322, n. 29); cf. Shaw (2001: 81, n. 1), quien toma distancia de esta postura.

2 Véase e.g. Green (1961: 14, 25, n. 31); Bradley (1998: 53-54); Urbainczyk (2008: 11); Bernard, Damon \& Grey (2014: 958); Barca (2020: 68).

3 Para una refutación de la tesis de Verbrugghe (1972), véase Coarelli (1981); Dumont (1987: 219-220).

4 Morton (2018b: 138).

5 Morton (2018b: 119): "the text's anachronism is indicative of a broader, and more problematic, disconnect between the Sicily of Diodorus' Bibliotheke and reality".

6 El valor histórico del relato diodoreo de la primera guerra servil también ha sido cuestionado mediante otras líneas argumentativas de la corriente historiográfica señalada precedentemente, las cuales pueden complementarse y combinarse diversamente en la formulación particular de cada autor: la impugnación de la supuesta fuente utilizada por Diodoro, es decir, Posidonio de Apamea (Manganaro, 1967; Verbrugghe, 1974); el rechazo de la narrativa diodorea desde el punto de vista de su descripción económica de Sicilia (Verbrugghe, 1972); la interpretación según la cual las fuentes numismáticas contradicen el relato diodoreo (e.g. Manganaro, 1967); la idea de que Diodoro escribió su narrativa de forma literaria para predisponer a los lectores contra el movimiento rebelde (Morton, 2013); la finalidad didáctica moralizante de Diodoro impediría utilizarlo como fuente histórica (Morton, 2018a; cf. Piantanida, 2021, donde rechazamos dicha postura). Estas otras líneas argumentativas no serán tratadas en el presente trabajo que se centra en el anacronismo de los equites y la presencia romano-itálica en Sicilia.

7 También existen fuentes numismáticas para la primera guerra servil elaboradas por los mismos esclavos rebeldes, pero para discutir el anacronismo de los caballeros y la presencia romano-itálica en Sicilia no son relevantes. Sobre las monedas acuñadas por el rey rebelde Euno-Antíoco y sus interpretaciones modernas de manera contradictoria con el relato diodoreo o complementaria de este, véase respectivamente Manganaro (1967; 1982 y 1983) y Sánchez León (2002; $2004 a$ y $2004 b$ ). Sobre el descubrimiento de monedas que fueron enterradas para ser tesaurizadas y preservadas de las dos revueltas serviles sicilianas, véase Manganaro (2012: 43-72).

8 La obra es una historia universal escrita en griego en el siglo I a.C. que estaba compuesta de cuarenta libros de los cuales solo se conservan enteros unos quince.

9 La edición del volumen que incluye los últimos libros fragmentarios y que pertenece a la colección de Loeb Classical Library, Walton (1967), no distingue los fragmentos procedentes del libro XXXIV de los del XXXV. En cambio, la edición y traducción de Goukowsky (2014) para la colección de Les Belles Lettres los separa y ubica la narrativa de la primera guerra servil en el libro XXXIV. De todas formas, en virtud del mayor peso relativo de su tradición, en este trabajo citamos los fragmentos diodoreos siguiendo el criterio de enumeración de la colección de Loeb y las traducciones al español que escribimos son nuestras, elaboradas a partir de su original en griego clásico, cuyo texto tomamos del TLG.

10 La colección conformaba una antología que, en un número desconocido de volúmenes, compilaba pasajes de historiadores antiguos bajo cincuenta y tres temas, de los cuales solamente nos han llegado cinco, véase Roberto (2009).

11 Véase Pfuntner (2015), quien destaca el rol de Focio como autor al reunir temáticamente, conforme a sus propios intereses, los pasajes diodoreos sobre las revueltas serviles originalmente dispersos de forma analística en los libros XXXIV y XXXVI, para crear la historia de las insurrecciones que en sí misma no había escrito Diodoro.

12 App. BC 1.3.22; Brunt (1973: 131-133); Crawford (1982: 121); López Barja de Quiroga (2004: 114-115, 129); Konrad (2006: 171-172); Lintott (2006: 80-82).

13 Véase e.g. Canfora (1999: 53, n. 2), quien sostiene que se trata de un error de Posidonio; Manganaro (1980: 438); López Barja de Quiroga (2004: 110); Pinzone (2012: 144 y 2015: 358-359); cf. Sacks (1990: 211-212), que discute la opinión convencional sobre el supuesto sesgo anti-ecuestre de Posidonio.

14 En la traducción de estos vocablos coincidimos con Capozza (1974-1975: 34); cf. Walton (1967: 57, 75); Shaw (2001: 81, 89); Goukowsky (2014: 84, 91).

15 Italici y su equivalente griego Italikoi pueden abarcar tanto a itálicos como a romanos, véase Fraschetti (1981: 60, 477,

n. 47); Capozza (1974-1975: 31); cf. Wilson (1966: 20).

16 D.S. $34 / 35.2 .33$. 
17 Mazza (1985: 102) sostiene que la denuncia estoica de Diodoro-Posidonio en términos morales por el comportamiento corrompido de los amos no es más que la conducta inherente a la nueva lógica económica de las relaciones de explotación entre amos y esclavos.

18 Nuestra interpretación coincide en este punto con la de Brunt (1971: 213): "In Sicily the luxury and cruelty of Italian latifondisti set a pattern to the local magnates and provoked the first slave war"; y con la de Capozza (1974-1975: 39): "Da tutto il suo racconto trapela, a mio avviso, una tradizione che interpretava la genesi della rivolta in chiave anti-italica, ancor meglio, anti-italiana."

19 Para una observación diferente, véase Goukowsky (2014: 323, n. 35).

20 D.S. 34/35.2.3 = 34/35.2.31: ippeîs (...) tôn Romaion; 34/35.2.27: tôn Italiotôn/Italikôn; 34/35.2.32: tôn Italikôn; 34/35.2.34: tôn katà Sikelian Italikôn.

21 La mayoría se inclina por sostener la tesis de una numerosa presencia de latifundistas itálicos y romanos en la Sicilia de mediados del siglo II a.C., en este sentido véase Carcopino (1906: 159); Pareti (1953: 294-295); Fraschetti (1981: 53-61); Coarelli (1981: 10, 15); Mazza (1981: 30-38); Dumont (1987: 213-217). Otros autores la rechazan, al respecto véase Frank (1935: 64), para quien el arribo importante de itálicos (del sur) solo se produce luego de la guerra social; Manganaro (1972: 452), según el cual un aflujo más intenso de itálicos y romanos sucede tras la lex Rupilia, ya concluida la primera guerra servil; Verbrugghe (1972: 542-545). Por otra parte, Sacks (1990: 148-151), remarca que, mientras las alusiones a los terratenientes itálicos son de carácter general, con un anacronismo evidente, y por lo tanto dudosas, pero no necesariamente falsas, ya que pueden pertenecer a una tradición local (siciliana) que culparía de la revuelta a los romanos e itálicos y a la cual Diodoro se adscribiría; por el contrario, las referencias a los propietarios sicilianos son específicas y con narraciones ricas en detalles (como el caso de Damófilo).

22 Soraci (2016: 61) señala que la lengua latina tendió a juntar Sikeloí y Sikeliôtai uniformándolos en una sola definición, Siculi, y que la distinción étnica entre esos dos grupos hecha por la lengua griega, durante los últimos siglos antes de Cristo fue perdiendo gradualmente sentido entre los propios sicilianos.

23 Véase e.g. Walton (1967: 53-91); Capozza (1974-1975: 38); Coarelli (1981: 10); Mazza (1981: 38); Sacks (1990: 142-154); Canfora (1999: 25-51); Shaw (2001: 80-93); Goukowsky (2014: 84-99).

24 Trad. de Villar Vidal (1993: 298).

25 Véase Wilms (1885: 22-24), quien considera que Floro y Orosio son derivaciones complementarias de Livio, e integrándolos con las Períocas intenta reconstruir el contenido probable de su relato perdido de la primera guerra servil; Pareti (1927: 63) y (1953: 293); Green (1961: 29); Forrest \& Stinton (1962: 90); Coarelli (1981: 12); Mazza (1981: 460, n. 7). Sin embargo, esta postulada dependencia liviana de Floro podría resultar abusiva, pues ha sido debidamente señalado que Floro no escribió toda su obra utilizando únicamente la historia de Livio ni hizo un simple resumen de ella, véase Forster (1947: x-xi); Jal (1967: xxi-xxx); Stampacchia (1976: 22); Hinojo \& Moreno (2000: 32-42).

26 La crítica erudita a menudo distingue, sobre todo para la primera guerra servil, la tradición posidoniana (Diodoro) de la liviana (Periocas, Floro, Orosio, Julio Obsecuente y Frontino) debido principalmente a las distintas cifras que brindan de las tropas rebeldes (D.S. 34/5.2.18 da un número total de doscientos mil; Liv., per., 56 habla de setenta mil esclavos al mando de Cleón, que era el otro líder de la revuelta; Flor. 2.7.6 dice que Euno formó un ejército de más de sesenta mil hombres), véase e.g. Rathke (1904: 21); Pareti (1927: 46). Algunos historiadores consideran que las cifras dadas por la períoca 56 y por Floro son complementarias, véase Verbrugghe (1972: 548, n. 19); y especialmente Coarelli (1981: 11-12).

27 Trad. de Hinojo y Moreno (2000: 263).

28 Como las califica Wilson (1966: 20), quien, no obstante, afirma (1966: 19) que para comienzos del siglo II a.C. ya había una apreciable emigración de romanos e italianos a Sicilia.

29 CIL I $551=C I L \mathrm{I}^{2} 638=$ CIL X $6950=I L L R P$ I $454=I L S$ I 23.

30 Mommsen (1863: 154-155); Westermann (1955: 65); Fraschetti (1981: 57-59); y más recientemente esta interpretación se ve respaldada por Bernard, Damon \& Grey (2014: 958-959); Adamo (2016: 85); de manera diferente Wiseman (1964: 36); Verbrugghe (1973: 30).

31 CIL I $533=$ CIL I ${ }^{2} 612=$ CIL X $7459=$ ILLRP I $320=$ ILS I 864: Italicei L. Cornelium Sc[ip]i[one]m honoris caussa. Wilson (1966: 20) indica que es probable que estos itálicos fuesen terratenientes - de manera similar Fraschetti, 1981: 56- y que el principal valor de la inscripción reside en que prueba que los colonos procedentes de Italia ya habían llegado hasta una pequeña ciudad en la parte norte de la isla, pasando Siracusa y la costa oriental.

32 Si en la narrativa diodorea los esclavos-pastores son incitados al bandidismo por sus amos para ahorrarse su manutención, conservando aquellos el botín; en cambio, en el fragmento de Juan Antioqueno los amos lo hacen para enriquecerse, pues son ellos los que se quedan con el botín y se apoderan de la isla. Por otra parte, Estrabón no menciona ninguna inducción o participación de los amos (en este caso romanos) en el bandidismo, el cual parece ser una actividad por cuenta de los propios esclavos-pastores. Al respecto, véase Capozza (1977: 406-408); Sánchez León (1991: 14-15); Pinzone (2012), 
este autor habla de una alianza y solidaridad entre domini y servi-pastores y la relaciona con otros casos, según él, similares de la historia romana.

33 Morton (2018b: 115): "the anachronism was inserted because the author did not understand the events he narrated or their immediate historical context”.

34 Véase e.g. Volquardsen (1868); Schwartz (1903); Wilamowitz-Moellendorff(1907); y más recientemente Hornblower (1981: 28): "This slavish dependence on his sources (...)"; Stylianou (1998: 49): "a mere epitomizer and an incompetent one at that".

35 Véase e.g. Sacks (1990); Chamoux (1990); Ambaglio (1995); Corsaro (1998); Green (2006); Rathmann (2016); Muntz (2017).

36 Chamoux (1990: 246); Bertrac \& Chamoux (1993: xxvii-xxx); Green (2006: 25).

37 Sobre la autopsia (acción de ver con los propios ojos) como fundamento de credibilidad histórica en la historiografía antigua, véase Corsaro (1998: 413-420); Yarrow (2006: 81). Sobre la importancia que le atribuye Diodoro, véase D.S. 1.4.1, donde -con el objetivo de convertirse en testigo ocular de los lugares cuya historia escribe- afirma haber recorrido gran parte de Asia y de Europa. 